\title{
Competition in optics for students: organization and realization of the practical and theoretical tours
}

Galina Romanova, Tatiana Tochilina, Alexey Bakholdin

Galina E. Romanova, Tatiana V. Tochilina, Alexey V. Bakholdin, "Competition in optics for students: organization and realization of the practical and theoretical tours," Proc. SPIE 9793, Education and Training in Optics and Photonics: ETOP 2015, 979320 (8 October 2015); doi: 10.1117/12.2223190

Event: Education and Training in Optics and Photonics: ETOP 2015, 2015, Bordeaux, France 


\title{
Competition in optics for students: organization and realization of the practical and theoretical tours
}

\author{
Galina E. Romanova*, Tatiana V. Tochilina, Alexey V. Bakholdin \\ Applied and Computer Optics Department, \\ ITMO University \\ 197101, 49 Kronverkskyi pr., Saint-Petersburg, Russia
}

\begin{abstract}
All-Russian competition in optics and optical engineering has been carrying out for several years. Leading Russian universities and institutes that teach in different areas of optics take part in this event. One of the main features of this event is that participants may be students of all years (except post-graduate students), and the exercises of the competition include many tasks involving different optical disciplines (applied optics, lasers, optical devices and instruments, geometric optics, etc.).

One of the main requirements of the Education Ministry to such events is that the competition must include both practical and theoretical parts. Practical part usually includes several tasks, and each task is a demonstration of an optical phenomenon or an optical instrument or device and involves questions concerning the demonstrated experiment. Theoretical part is a set of tasks and questions that should be solved and answered in written form. Organization committee and judges which are the members of teaching staff of different universities prepare complex theoretical tasks and arrange a set of practical questions. Nevertheless the set of task may include simple questions which can be solved using basic knowledge of optics, observation and erudition. Thus, such competitions help to discover the most talented and motivated students which have great potential.
\end{abstract}

In the report the problems of organization and carrying out of such competition in optics are discussed. Examples of tasks which were used in different years and also retrospective of the competition are presented.

Key words: optical engineering, education, competition in optics for students

\section{INTRODUCTION}

All-Russian students' competition (RSC) in optical engineering are being held annually. In this competition students can participate who study optical engineering in specialties "Laser technology", "Laser systems in missilery and cosmonautics", "Optical electronic systems and instruments", "Optical technologies and materials".

The founder of this event is the Ministry of Science and Education of Russian Federation, The Council of Educational and Methodical Union on Education in Optical engineering. The organizers of RSC are Saint-Petersburg National Research University of Information Technologies, Mechanics and Optics (ITMO University) - one of the main educational institutions in Optical Engineering in Russia ${ }^{1}$.

The main goal of the competition is to motivate students, to show the wide range of optical tasks and experiments. Another goal is to help future employers and to the students' teachers and lecturers to choose the most creative and perspective persons.

\section{HISTORY AND FORMS OF TOURNAMENTS OF THE COMPETITION}

In 2005 year all-Russian students' contest started again after the great pause. In different years from 2005 to 2011 many students from various Russian, Ukrainian and Belarusian institutes and universities had been participating in the competition. Many features of organizing of such an event are defined by the timing and the numbers of participants.

From the 2005 the contest was organized consisted of two parts - individual and team championship. Team championship was in the form of blitz tournament. The last was the answers on different questions on-line in distant education system $(\mathrm{CDE})^{2}$ with automatic results processing. Blitz tournament which was organized in $2005-2008$ years had different forms: biathlon and classical test.

*romanova_g_e@_mail.ru; phone: +7(812)595-41-46; aco.ifmo.ru

Education and Training in Optics and Photonics: ETOP 2015, edited by Eric Cormier, Laurent Sarger Proc. of SPIE Vol. 9793, $979320 \cdot$ C 2015 SPIE, IEEE, OSA, ICO · doi: 10.1117/12.2223190 
In 2007 year extramural participants were engaged in the competition for individual and team championship. The participation in absentia allows using only tasks for written solving and electronic tests.

The form of Biathlon tournament gets its name from the sports events. As in sports in this case there is the main track of questions: if all answers are right the participants follow the main and the fastest way to the finish and get the maximum points. If the participant makes a mistake when solving some question he gets an additional "penalty" question which is only in this additional trajectory and no in the main track. This additional "penalty" question is simpler than the main questions and gets fewer points than the main one if the answer is correct. After the correct answer the participant returns to the main line. If the answer is wrong another one "penalty" question is offered simpler than the question from the first additional track. After the second additional question in any case (wrong or right answer) the participant comes back to the main track.

Examples from the main track are shown in the figure 1.

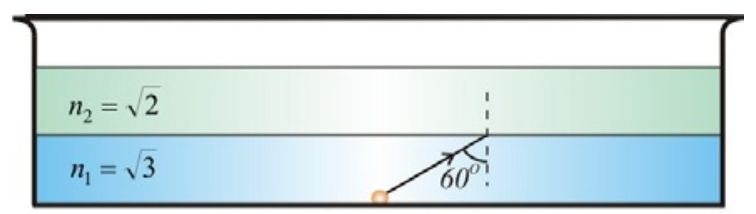

In the vessel there is some solution with refraction index $n_{1}$, above this another liquid with refraction index $\mathrm{n}_{2}$ are poured. On the bottom of the vessel there is the light source. What is the angle of the ray coming out from the vessel if the angle of incidence is 60 degrees?
the ray does not exit from the liquid
40 degrees
O 85 degrees

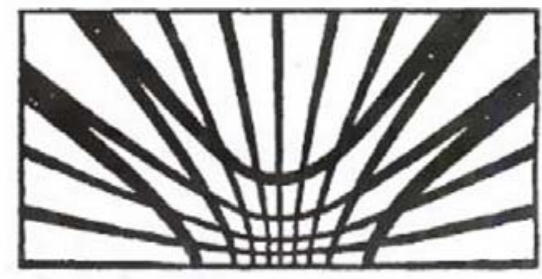

What is the limit value of the f-number for the optical system to fulfill the sine condition?

Write the answer.

Fig. 1 Examples of the main trajectory questions in biathlon blitz tournament: a) test form; b) "open answer" form

The examples from the first additional circle are shown on the fig. 2

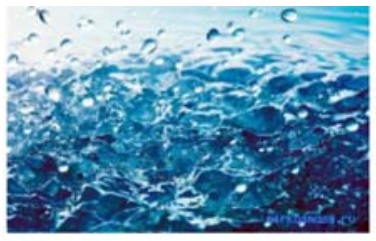

What glasses are necessary for the person who can see well under the water?

with diverging lenses

with focusing lenses

$O$ the person doesn't need glasses

with plane glasses

$a$

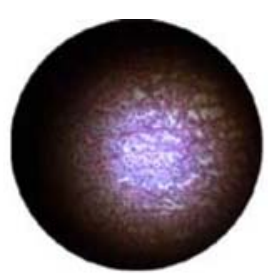

What illumination of specimens provides the best resolution of the microscope?

Ultraviolet illumination

Infrared illumination

Visible range illumination

$b$

Fig. 2 Examples of questions of the first additional circle in biathlon blitz tournament: a) about the eye and vision; b) about microscope resolution

The example of the question from the second additional circle are shown on the Fig. 3 
Rainbow colors of soap-bubbles appear because of ....

O Interference

O Refraction

O Diffraction

The promotion campaign of the cleaner

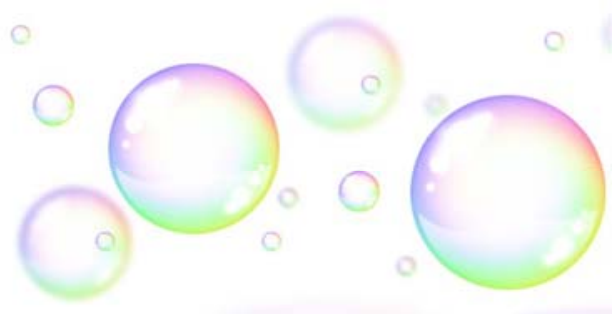

Fig. 3 An example of a question of the second additional circle in biathlon blitz tournament

Another form of the blitz tournament is test. This form can be rather easily organized for extramural participation. That test could include from 20 to 50 questions of different difficulty level that required both knowledge of optics and erudition and observation. Forms of questions are:

- solving rather simple tasks. In that case the answer is the number;

- questions with text answer;

- tests with choosing the right answer or answers;

- tests where it's necessary to put together corresponding data from two sets.

Weights which correlate with the difficulty of the task or question are defined before and written in the electronic system so the participant can see the scored points immediately. The examples of the tasks are shown on the fig. 4.

Rank these substances according by the
light velocity inside them:
$\square$ diamond
$\square$ water
$\square$ glass
$\square$ air

$a$

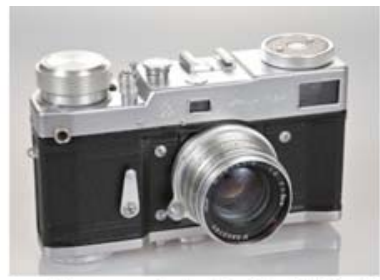

It's known for some photoobjective its focal length and f-number. What characteristic is necessary to the objective description to make it full? Several correct answers are possible. 1 Angular field in the object space

Frame size

Numerical aperture in the object space

Linear magnification $b$

Fig. 4 Examples of questions of blitz tournament: a) weight coefficient 2, b) weight coefficient 1

In some years optical crossword was used as one of the tours. The main feature of this competition is that we can use only optical terms, names of scientists in optics, names of optical instruments and devices, optical phenomenon, optical elements, etc. This tour traditionally attracts interest, because even the scores for this tour are not so high the participants find out many new interesting facts and things about optics. On the figure 5 the cross grid (for filling in Russian) and some questions (in English) are shown. The counting of scores in this competition can be also automatic because the answer are considered as correct if the "key" letters are coincide with the right answer. For different words the number of the key letters may be different and usually these letters are chosen so to allow considering answer as correct even if there are grammar mistakes. 


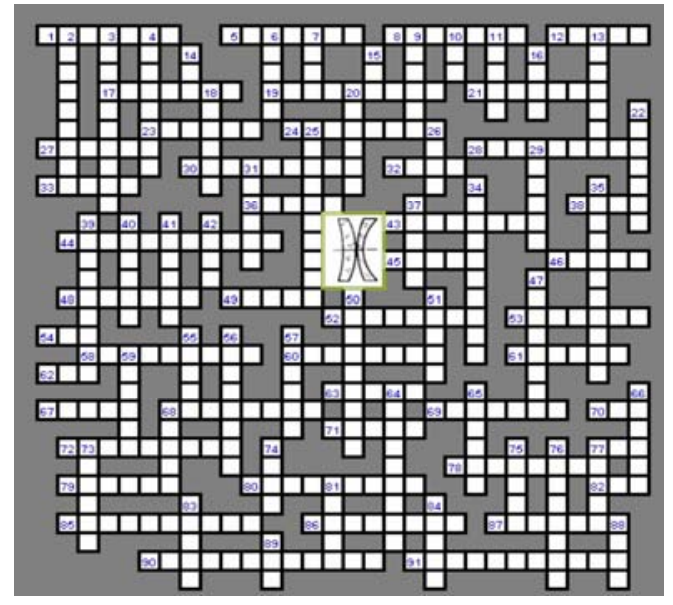

$a$

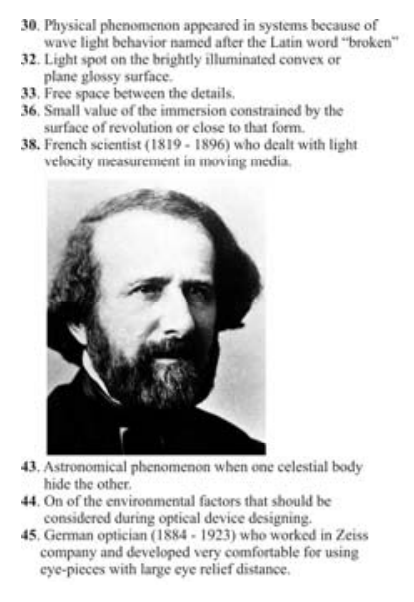

52. Light-sensitive surfice of the eye

From the Greek word "relief": method of getting the stereo

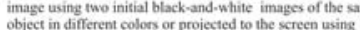
the light filters.

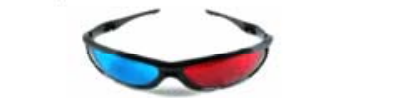

54. From the Greek "straight": the unit vecter

58. Optical phenomenon
6. The substance or the device that is emitting the radiation of can emit the radiatio

61. The ativiliary device used to take pictures with large time

62. Form of the surface which has different optical power in

different eross section

3. Germian mitstimatician (17777 - 1855), astronomer, geodesis and physicist, forcign fellow (1802) and foreign honorary
member (1824) of the Peternburg Academy of Sciences uhto developed an ideal optical system theory.

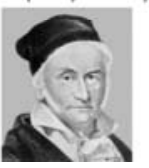

$b$

Fig. 5 An example of a question of the second additional circle in biathlon blitz tournament: a) cross grid; b) questions (fragment).

\section{THE COMPETITION TODAY}

Nowadays RSC are held twice a year: autumn term is for the region tour, spring is for all-Russian tour. In allRussian competition the main leading universities and institutes who teach in optics and optical engineering take part.

Each tour of the competition includes two parts: practical part and theoretical part. Depending on the timing and the number of participant both tours can be held in one day or in different days. This organization features defines the number and the complexity of the tasks in the competition.

The tasks may include questions on different optics topics: lasers, geometrical optics, optical design, aberrations, photometric and illumination engineering, designing and constructing of parts of different optical devices, etc.

Approximately one half of the tasks related with basics of the optics and theoretical basics of optical engineering, another part of the tasks are specifics of engineering in different areas (aberration calculation, mechanical design and errors of manufacturing, optical technology and manufacturing, laser technology and so on). This part is named theoretical tour despite the fact that all tasks are related with practice of optical device designing and with real tasks that optical engineer are dealing with.

Before recently the event included only so called theoretical part, and in that case the time for solving the tasks was about $4-5$ hours and the number of tasks was $15-22$ (in different years). The larger number of the tasks allowed to evaluate the participants more accurately with grater difference between the scores.

Now when there are practical and theoretical tours the tasks in theoretical tour was decreased to the number 10 12. Additionally before the tournament starts the maximum scores for the whole tour is fixed. For instance for the spring 2014 it was agreed that maximum score for the practical tour was 40 points and for the theoretical tour was 60 . In all cases the maximum of the scored points for both tours is equal to 100 . 
On the figure the object $\mathrm{AB}$ and its image $\mathrm{A}^{\prime} \mathrm{B}$ ' formed by some thin lens are shown.

Find:

1) the position of the superposed principal planes

2) the position of the optical axis

3) focal length of the lens

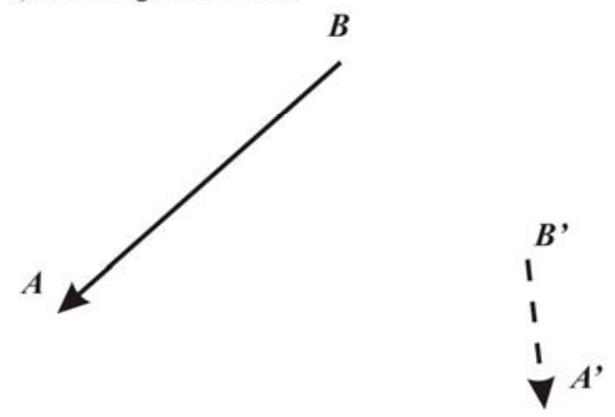

$a$
During the course project a student should develop the mount for some photoobjective. The student has made some mistakes in the construction design. Find these mistakes on the sketch, explain them and offer the correct variant.

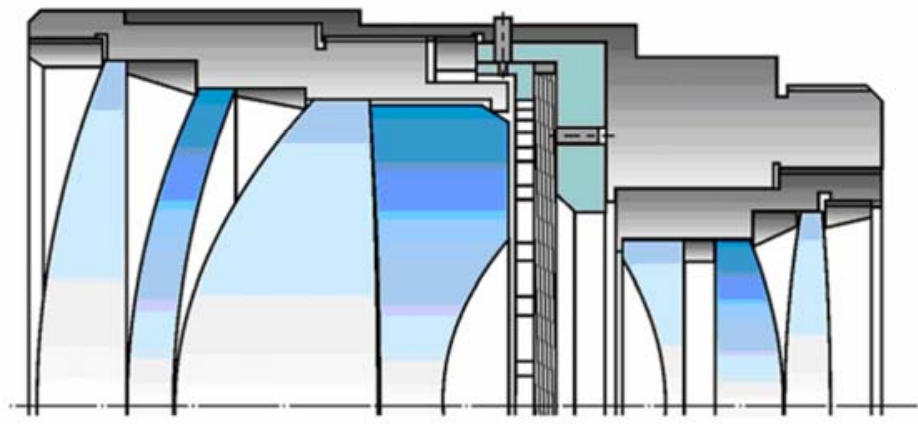

$b$

Fig. 6 Examples of the tasks: a) simple graphic task; b) the task on construction design.

Of cause the event is usually for the most motivated and intelligent students but in the set of tasks there are always very simple (relatively simple) tasks, often graphical tasks. For example, in some year in the set there was the graphical task shown on the fig. 6a. The example of the more complex task is finding the frame frequency for the highspeed camera if the frames of shooting the metal ball falling are given. Another example is about the optical mouse device and the maximum distance between the device and the surface when the device can work yet. The example of the task on construction design is given on the fig. $6 \mathrm{~b}$.

The number of tasks in practical tour depends on the number of the participants. It can be the question about optical element, optical testing method and adjustment of devices and so on. The questions include some explanation about the device and explanations of the task so the participants who see the device or the phenomenon for the first time are able to understand the task using their basic knowledge. The participants have some time after the explanation and presenting the question to give their answers in written form. If the number of participants is not so great the practical tasks can be connected with practical working with some optical device. For example, measuring some specimen using biological microscope. The task was to choose appropriate objective, do measurement of the object and evaluate the error. On the figure 7 the photos of the practical tour are shown.

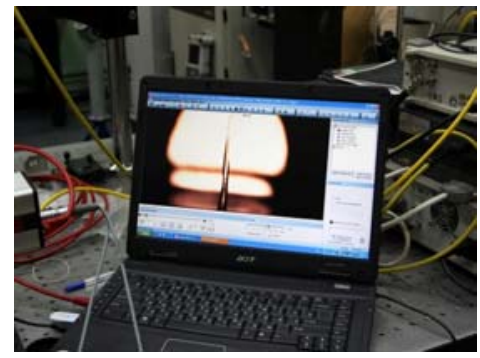

$a$

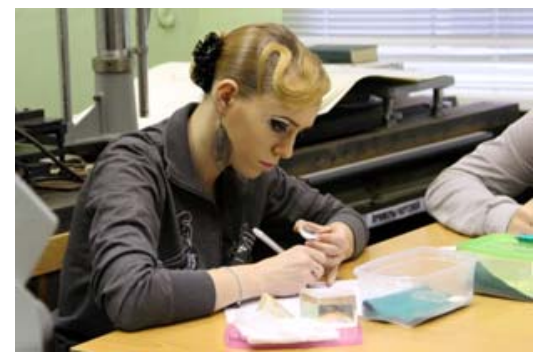

$b$

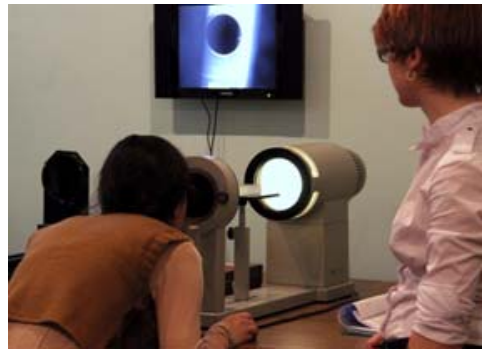

Fig. 7 The practical tasks: a) the question about the optical phenomenon; b) the question about the optical elements; c) the question about the optical testing method.

The Jury of the competition consists of the representatives from different universities. Usually the team from the university has the supervisor who is part of the Jury. The Jury checks the works of the participants. During this checking all works are signed not by the names of participants but with some special code, so during the checking process the Jury members don't know whose work they are checking. After the announcement of the preliminary results the participants have the opportunity to appellate. The special appellation committee considers the reasoned appellations and can increase the point for some solution. The practical tour tasks are checked by the author of the question and have no the possibility of appellation. After the appellation of the theoretical tour the final results are placed on the site of the event ${ }^{3}$. 
Organizing committee tries always to attract different specialists from various universities and the departments to the tasks composing. It allows offering various topics and showing different methods to the participants. Traditionally the Universities who are taking part in composing of the tasks and in checking (in the Jury) are Siberian State Geodesic Academy (Siberian State University of Geosystems and Technologies, Novosibirsk), Baltic State Technical University "VOENMECH" (Saint-Petersburg), Moscow State University of Geodesy and Cartography (Moscow), Bauman Moscow State University (Moscow), Saint-Petersburg State Electrotechnical University «LETI» named after V.I.Uliyanov (SaintPetersburg), Kazan National Research Technical University named after A.N.Tupolev (Kazan), Samara State Aerospace University (Samara) and others. In composing the tasks different departments of the University ITMO take part: Applied

and Computer Optics Department ${ }^{4}$, Department of the Optical Electronic Devices and Systems ${ }^{5}$, Department of Optical Materials and Technologies, Department of Computer Photonics and Videoinformatics and others ${ }^{1,3}$.

Integrated approach to the tasks composing allows to propose the tasks that can be solved by participants not only using specific knowledge and skills delivered in some certain university but using basic knowledge of optics that are common to all specializations inside the training direction "Optical Engineering" and the everyday experience, logics, observation and erudition.

\section{CONCLUSION}

The student competition in optics and optical engineering are great students' movement which gives the opportunity to communicate between the different universities and share the experience in education and optics. Such competitions help to increase the quality of the specialist education in optics and optical engineering and also to discover the most talented and motivated students which have great potential.

\section{REFERENCES}

1. en.ifmo.ru

2. $\quad \underline{\text { cde.ifmo.ru }}$

3. faculty.ifmo.ru/vso

4. aco.ifmo.ru

5. http://oeps.ifmo.ru/ 